\title{
The transfer of heritage modelling from research to practice
}

\author{
Jenny Richards ${ }^{1,2^{*}}$ and Peter Brimblecombe ${ }^{3}$
}

\begin{abstract}
Heritage science is an inherently practice-oriented field that aims to support our understanding, and conservation, of heritage. Research is commonly undertaken using laboratory or field-based methodologies, but given the ethical and scale constraints, over time and space, of these approaches, process-based models should provide a tool for exploring practical solutions. Unlike other fields, such as climate science and ecology, there appears limited engagement with modelling within heritage science. The characteristics and use of processed-based models published in the field is examined to explore tensions in using models to transfer understanding between research and practice. By examining models that investigate interactions between heritage materials and environment, we find that, at best, model outputs may be used by other researchers or occasionally by heritage institutions; or more commonly, the model's existence is used as a justification of research, yet without meaningful engagement within either the academic and heritage practitioner communities. Some models are unlikely to be used in practice as they have been developed at spatial or temporal scales incompatible with being truly applicable to objects or sites, or can seem to advance theory without engaging with practice. The uptake of models by researchers who rerun or change the code is rare. Models that seem to gain substantial use appear to benefit from graphical user interfaces that make them easy to run. Evidence of models in solving real-world conservation problems is hard to find. This may arise because practical applications are rarely reported in academic journal literature and open access publications. There is some evidence they are revealed in conferences and possibly internal heritage organisation reports, but this gray literature doesn't readily feedback into the development and refinement of existing models. It is likely the use of models would increase if mechanisms were available to support the development of user interfaces, training workshops and the ability of practical use cases to be fed back to the modelling community.
\end{abstract}

Keywords: Process-based models, Tangible heritage, Model use, Applicability, Bibliometrics, User feedback

\section{Introduction}

Modelling is widely applied in many science and social science disciplines e.g. [1, 2]. In the field of heritage science, this has been less common, despite the existence of books and journals such as Mathematical Modeling in Cultural Heritage [3] and the Journal on Computing and Cultural Heritage. Models are an abstract of reality and so present a simplified representation of a system. They will always be imperfect as a perfect model would

\footnotetext{
*Correspondence: jennifer.richards@sjc.ox.ac.uk

${ }^{1}$ St John's College, Oxford University, Oxford OX1 3JP, UK

Full list of author information is available at the end of the article
}

effectively be reality itself. However, by engaging with particular parts of a system, models allow specific theories, processes and practices to be explored under varying conditions. As such, they provide heritage researchers and practitioners with a powerful tool that enables us to both ask and answer questions.

In a very practice-oriented field such as heritage science, process-based models provide a tool for engaging with changes to heritage objects or sites e.g. [4-6]. These models, which represent parts of, or interactions within a given system, can be used to undertake highly varied experiments that would not be possible for practical or ethical reasons, due to the potential for damaging

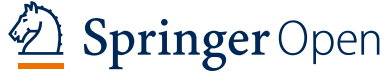

(c) The Author(s) 2022 Open Access This article is licensed under a Creative Commons Attribution 4.0 International License, which permits use, sharing, adaptation, distribution and reproduction in any medium or format, as long as you give appropriate credit to the original author(s) and the source, provide a link to the Creative Commons licence, and indicate if changes were made. The images or other third party material in this article are included in the article's Creative Commons licence, unless indicated otherwise in a credit line to the material. If material is not included in the article's Creative Commons licence and your intended use is not permitted by statutory regulation or exceeds the permitted use, you will need to obtain permission directly from the copyright holder. To view a copy of this licence, visit http://creativecommons.org/licenses/by/4.0/. The Creative Commons Public Domain Dedication waiver (http://creativecommons.org/publicdomain/zero/1.0/) applies to the data made available in this article, unless otherwise stated in a credit line to the data. 
heritage. As models are imperfect, yet could be used to inform decision making processes, heritage scientists need to think carefully about model applicability and usefulness. There is no prescriptive way to develop a model that is useful. Some models can advance theory e.g. [7, 8], while others might provide practical solutions to specific problems e.g. [9]. Additionally, a successful model within heritage science could enable a two-way transfer of understanding between research and practice, rather than just providing one-way recommendations on heritage conservation or policy. Within heritage science, traditional field and laboratory methods of experimentation on unique or valued objects and sites are highly constrained, so modelling could seem to be a good solution.

There are unresolved tensions in the use of models in heritage science [3]. The overtly theoretical basis of many modelling approaches can lead to models being perceived as artificial constructs, coded in obtuse mathematics or complex programming scripts. This can result in them appearing far removed from practical heritage management, with little day-to-day relevance to unique and valued objects or sites. The spatial or temporal scales of processes represented by the model need to be consistent with the key processes of change within heritage. Without this, results can seem of little relevance to heritage management. Indeed, models need to be usable by practitioners, not just researchers and model developers. If these tensions are not resolved, there can be resistance to modelling in the heritage field [3]. Resistance is unlikely to be resolved by just presenting more processbased models to the heritage community, so we need to reflect on why tensions may have formed and how they could be addressed.

In this paper we explore the tensions in modelling within heritage science by examining: (i) the characteristics of published models that transfer understanding between research and practice and (ii) how we can assess success of published models. Our focus is from an academic perspective, but it remains essential to examine the way models might be incorporated into practice.

\section{Methods}

A bibliometric approach was taken to review the use of theory and models in the published heritage science literature. These approaches are perceived as a method to quantify and assess research in a manner that can also capture interdisciplinary interactions between scientific communities [10,11]. Metrics associated with these approaches are now used by individuals to assess the success of research, e.g. the number of citations of a paper. These simple metrics are commonly popular among institutions and policy makers to determine the impact of research, but have faced criticism from those who argue that these metrics can be misused or are an inaccurate measure for judging the quality of research e.g. [11-15]. However, as outlined in the manifesto of Hicks et al. [16], quantitative bibliometrics can strengthen peer review when used alongside expert judgement, and if presented in a transparent manner. In heritage science, bibliometric approaches have recently been used to capture research published in a wide range of academic literature e.g. [17-19]. We examined publications using heritage models, and so adopted a similar approach, but are clear that this predominantly covers research rather than practice. Although we examined alt-metrics [20] in addition to classic journal citations, it still seems that practical achievements in heritage conservation are difficult to access.

A broad search of the peer-reviewed literature was conducted using Scopus, on 27th September 2021 (Fig. 1, Step 1). Search results were refined through a series of filters, as outlined in Fig. 1: Steps 2 to 4, based on the publication source (journal filter) and focus of the article (content filter).

The journal filter was required to limit the breadth of applications and contexts in which both the terms 'heritage' and 'model' were used (e.g. 'heritage' used to refer to genetic histories within the field of biology). Many papers returned in the initial search were not relevant to the field of heritage science. This filter focused search results on papers associated with heritage science publications (Fig. 1, Step 2).

Two content filters were applied to remove papers without a focus on process-based models (Fig. 1, Steps 3 and 4). We focus on process-based models (e.g. models that capture chemical, biological or physical changes to heritage), as they can assess mechanisms and rate of change over time in both theoretical and practical contexts. This gives them the potential to investigate, develop and test changes in heritage. In Step 3 , papers that had a focus on either photogrammetry, virtual reality, augmented reality or 3D modelling were removed as they often do not explicitly capture the process of change. Then, Step 4 removed papers that (i) were based on non-process-based models, e.g. tourism models, business models; (ii) used monitoring, field or laboratory methods, rather than modelling; (iii) were a review article and therefore not using/developing a specific model; (iv) used 'model' as a word to mean an example object or site rather than a methodology.

A total of 39 process-based modelling papers were returned after Step 4 (Additional file 1: Table S1). These were read to assess the following characteristics of the model: type, process, motivation, inputs, outputs for theory and policy and flexibility in other contexts. The 


\section{Model analysis}

\begin{tabular}{|l}
\hline Step 1. Scopus search: TITLE-ABS ( "heritage" AND "model*" ) \\
$\qquad$ Return: 14385
\end{tabular}

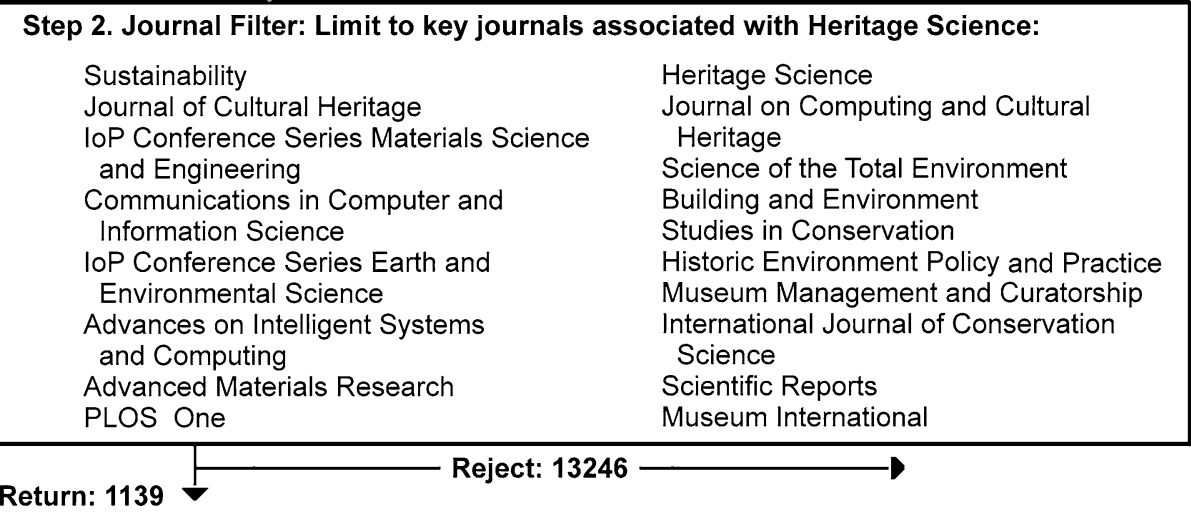

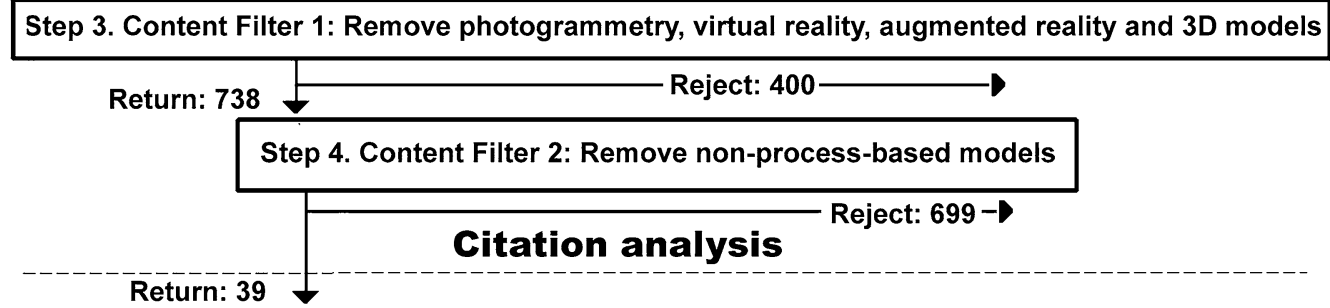

Step 5. Citation Filter: Highly cited papers ( $>20$ total citations and an average of $>4$ cites per year)

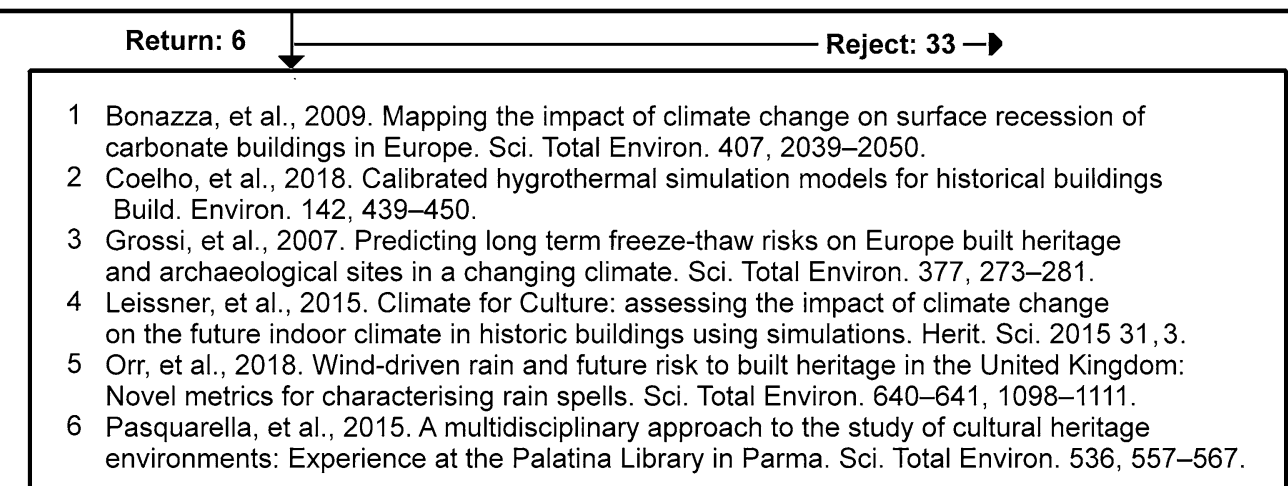

Fig. 1 Flow chart showing the stepwise criteria of identifying papers included in this study. The number of papers considered at each stage is noted

usefulness of a model was assessed from its potential for translation into practical heritage outcomes.

Step 5 identified six highly cited papers, based on total and average annual citation, for citation analysis (Fig. 1). Given the small number of papers returned, these are used as exemplars, and analysed in terms of the referenced and citing papers. Referenced papers were assessed in terms of their field or discipline and frequency of occurrence in the modelling paper and citing papers in terms of the frequency and location of the citation (e.g. introduction, methodology, discussion) and the subject field.

This bibliometric approach does not capture the grey literature (i.e. non-indexed conference proceedings, internal reports, policy documents, etc.), which may reflect more practical applications of model-based research. It is difficult to analyse data from conference proceedings, internally published museum reports etc. because the relevant bibliometric data is hard to access. We necessarily focus on the academic end of the 
spectrum of model use and trace models towards the theory-practice interface. This leads to an overemphasis on research-based use of the models in our analysis. However, to capture field-specific publication practices [16], we tried to engage with grey literature, and use specific examples we were able to access, to show the use of models in practice.

\section{Results and discussion}

\section{Models within heritage science literature}

Scopus search results returned 14,385 items after Step 1 (Fig. 1), 1139 of which were from a range of publications commonly associated with heritage science (Fig. 2, outer ring). Some $42 \%$ of papers (481) were in journals and large conference series with a broad scope (e.g. Sustainability and IOP Conference Series), 18\% (201) in the Journal of Cultural Heritage and 11\% (120) in Communications in Computer and Information Science. Of these 1139 articles, 35\% (400) focused on either photogrammetry, virtual reality, augmented reality or 3D modelling. The substantial volume reflects the current trend to digitise heritage for recording and accessibility purposes, but the models in these papers do not primarily assess processes of change to heritage, so were excluded from further analysis.

Only 39 papers were identified as focusing on process-based models (Fig. 2, inner ring), and these were most frequently found in the Journal of Cultural Heritage (11), Building and Environment (7), Science of the Total Environment (7) and Heritage Science (6). A range of model types were present, including computational fluid dynamic [4, 21-24], thermodynamic [25,
26], biological [27] and fuzzy logic [28-30] models. The models described had been used to capture processes such as moisture regimes [31-33], pollutant deposition $[4,34]$, wind-driven sediment abrasion [5, 21, 23] and salt weathering $[35,36]$. Our selection does not capture all process-based models that relate to heritage, but our dataset encompasses a range of model types, applications and approaches that give a reasonable understanding of the current state of modelling within heritage science.

The models missing from our analysis highlight a general challenge of finding relevant research faced by those engaging with heritage science. The interdisciplinary nature of the field means that many studies are published in non-heritage and subject specific publications (e.g. Earth Surface Processes and Landforms; Communications on Pure E Applied Analysis), making it difficult and time consuming for researchers and practitioners to find and engage with such information.

\section{Characteristics of a useful model in the heritage sciences}

The assessment of the 39 process-based modelling papers suggested four main characteristics that contribute to a model's usefulness: (i) the model's theoretical underpinning; (ii) the ability for the model to investigate process; (iii) the spatial and temporal scale of the model and (iv) the usability of the model.

(i) Theoretical underpinning

All models assessed in this study engaged with theory to some extent, with theory as a representation of the processes of change e.g. $[37,38]$. In most models, theory focused on processes in a specific context.

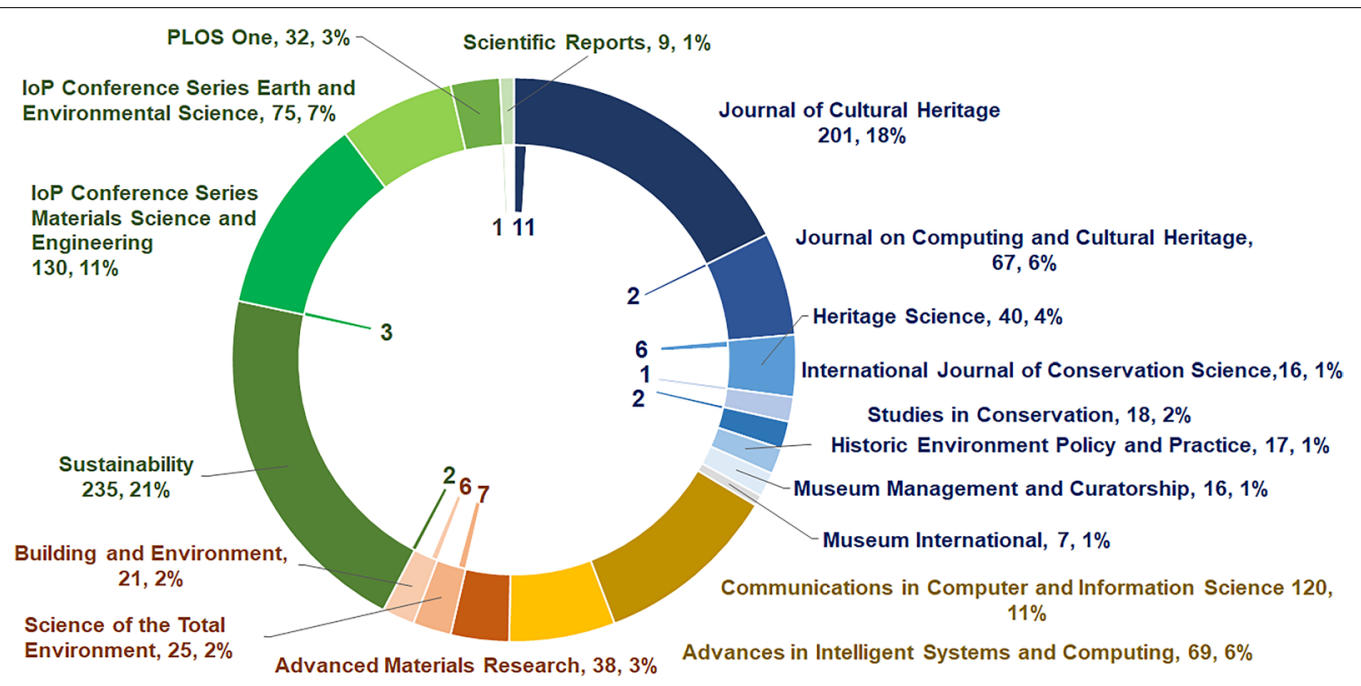

Fig. 2 The number and proportion of papers published in each journal commonly associated with the heritage sciences after the initial broad search (Step 2-outer ring) and assessment for relevance (Step 4-inner ring). Colours indicate groups of journals as determined by the authors: blue $=$ journals with specific heritage focus; yellow/orange $=$ journals without a specific heritage focus; green $=$ mega-journals 
For example, Hussein and El-Shishiny [21] developed a computational fluid dynamic model to investigate wind and sediment abrasion of The Sphinx at Giza, Egypt, while Ghosh et al. [39] used an environmental fluid mechanics model to simulate chemical erosion and abrasion of the Apollo theatre in Delphi, Greece. Although in these examples outputs are easily transferred to practice, the applicability is constrained to a single site or object. In journals such as Journal of Cultural Heritage and Science of the Total Environment, research that lacks broad relevance and applicability, such as a case study, is to some extent discouraged. The applicability constraints of context-specific models mean that these could be thought of as a form of case study, reminding us of the need for models to remain generalisable.

Models with a strong theoretical underpinning, such as three models published in Building and Environment by Chatoutsidou et al. [40], Grau-Bové et al. [4] and Kompatscher et al. [41], could be applied to assess processes in original and new contexts. These could be applied to indoor contexts in many locations, making them highly adaptable and aiding the translation of research to practice. Models in heritage science with this theoretical basis strike a balance between incorporating processes important to specific heritage sites and objects but remain flexible enough to be effectively applied to more than a single site. Adaptable models would help investigate the efficacy of theories by testing systems under a myriad of conditions, pushing our understanding of the limits of theory.

\section{(ii) Ability to investigate process}

We found that models needed to investigate processes that are relevant to, and could impact, heritage, for research to be translated into practice. The motivation behind almost all models was to understand a specific process that might cause damage or a loss of value to heritage or investigate conservation treatments. For example, Rihosek et al. [42] assessed gravity as a factor driving decay at Petra, Jordan; Hussein and El-Shishiny [21] and Pineda et al. [23] modelled the impact of aeolian erosion; and Zhao et al. [37] and Cabello-Briones et al. [29] tested innovative, but potentially risky conservation strategies. These are examples of useful models for assessing the resilience of heritage under a variety of pressures that would not be ethical to test on the actual heritage.

Intuitively, it seems likely that the ease in which the translation of outputs between research and practice should be dependent on the model design. We would expect that models originally designed with a practical outcome can facilitate the transfer of knowledge to action, whereas if the model output is more theoretical, this can take longer.

\section{(iii) Spatial and temporal scale}

The models we examined functioned across a wide range of temporal scales from hours and days e.g. [35, $39]$, years and decades e.g. [4, 23] and over the 21st century e.g. [5, 9, 43-45]. Similarly, a range of spatial scales were modelled from processes occurring inside/on heritage materials e.g. [34, 35, 37], building and sites e.g. [5, $26,28]$ and regions and continents e.g. $[43,46]$.

In theoretical models where the modelled process was removed from the heritage context, we noted that the scale of the model was often prescribed by the underpinning theory, rather than the processes of change to heritage. While a theory driven approach can provide useful insights into processes occurring to heritage, unless the scales capture the impact of the process on heritage, it can be difficult to transfer results in practice or policy. The outcome of such mismatches in scale results in theoretical models receiving few citations; with those gained typically arising from other modellers. Therefore, for models to be usefully applied to heritage, the modelled spatial and temporal scales need to be relevant to the impact of processes of change relevant to the heritage value and utility associated with sites and objects. These scales can be used imaginatively, as shown by Marcon et al. [32] who used the timescale of a concert to model the moisture in a wooden violin.

The challenge of scale will likely resonate with concerns recently expressed in the Preface to Mathematical Modeling in Cultural Heritage: MACH2O19.

"The main obstacle in using mathematical models is the lack of contacts and common background between different communities... even if a lot of research work has been done in modelling the behaviour of building subjected to strong mechanic stress, the scale of interest for cultural heritage is quite far from the typical scales considered in civil engineering." (Bonetti et al. [3], Page v).

This quotation highlights the challenge many nonheritage modellers face when grappling with concepts of scale in the field of heritage science. The practical nature of the discipline means that models need to be based on scales that enable practical output. Without this, although the model may capture processes occurring on historic material, it becomes an exercise within material science rather than heritage science.

(iv) Practical application

The three characteristics discussed above increase the likelihood for the model to be applied in practice. The model application is then dependent either on the output of the model being in a format that can be applicable 
to the heritage of interest or that the model can easily be run by users for their specific site or object.

Model outputs were presented in a variety of forms, typically showing processes of change across time e.g. $[6,27]$ or space e.g. [5, 46], using graphs [25, 33, 47], Tables [9, 25] and maps [43, 46]. Model outputs that were concisely presented and in a format that could be intuitively interpreted without relying on constant reference to text e.g. [48] appeared to be more applicable. The application of model results was aided when results could easily be interpreted with reference to multiple sites. For example, outputs mapped over regional scales by Grossi et al. [43] and Bonazza et al. [46] have gained over 100 citations each. However, outputs that are readily applied to new contexts risk being used without due consideration of the associated limitations and uncertainties. Therefore, model outputs need to be very clear about modeling constraints so that they are applied appropriately.

Models may be even more flexibly applied when they are re-parameterised and run for the specific site or object. However, the ease with which users were able to run the models varied substantially. Some models such as IMPACT, ECOS-RUNSALT and EnvCul, have been developed to have graphical user interfaces (GUIs), which means that users do not have to engage with potentially complex computer code, so can instead apply the model through an intuitive interface.

IMPACT is a very simple online calculator and has been often used e.g. [49-51] and is found among practical rather than academic applications, with reports published in journals typically used by practitioners.

RUNSALT provides a GUI developed by Bionda [52] that has facilitated the wider use of the ECOS thermodynamic model [53], which itself was applied for salts in stone [54] by adapting a well-known electrolyte thermodynamic model for aerosols which determines the phase and water content of salts [55]. ECOS-RUNSALT is widely used, most often by academic researchers, though with some use by central laboratories associated with cultural heritage (e.g. Royal Institute for Cultural Heritage KIK-IRPA, Brussels, Belgium and Scientific Laboratory, Federal Monuments Authority Austria, Vienna, Austria) [e.g. 25, 35]. As with easily applicable results, models such as ECOS-RUNSALT and IMPACT can risk being run with little understanding of the underpinning theory.

The EnvCul model (https://envcul.nilu.no/) is a condition model with an intuitive GUI that can be used to assess relationships between the condition of cultural heritage objects, environmental factors and conservation costs. Results can easily be seen as applicable to practical decision making and have been used to publish in academic literature [e.g. 9, 56].
Most models we reviewed revealed the underlying equations, and more rarely the computer code, yet gave little information on implementation. Some model code was open access e.g. [5], but it is always challenging to use someone else's code. It is time intensive to make code user friendly and readable, and even more difficult to develop GUIs. Indeed, outside academia, this is a profession valued in its own right, while in academia, such activities have few rewards in terms of traditional academic metrics. This may explain why few models in heritage science have been developed to such a user-friendly level. Therefore, even if the authors suggest the model could be adapted and applied to other sites and objects e.g. $[5,9]$, this is rarely acted upon by researchers outside of the original research team.

\section{Information pathways in highly cited papers}

The six example papers identified in Fig. 1, Step 5, were cited between 22 and 119 times. The modelling papers drew on research published from fields, including climatology, atmospheric sciences, physical geography, public health, computer science as well as heritage science. For example, the referenced papers in Pasquarella et al. [22] were from computing, public health and heritage while Grossi et al. [43] drew on research published in physical geography and geomorphology. The fields associated with the referenced papers show the broad academic basis that heritage science draws upon for theory, process and method. The many approaches being used can mean it is difficult to convey to those engaging with heritage science why a chosen theory or method is appropriate or valuable.

In contrast to the referenced papers, the citing papers were predominantly in journals associated with cultural heritage or the built environment, with some citations in environmental management and climate oriented publications. This asymmetry suggests that research within heritage science is mainly funnelled into further heritagebased research, rather than re-engaging with the numerous fields from which this research is drawn.

It was disheartening to notice that few of the citing papers engaged in a substantive way with the modelling papers. The modelling papers were typically cited once within the introduction of the citing paper, without further reference (Fig. 3). They were typically used to list examples or justify their research with minimal engagement with the original model or its outputs. Only $8 \%$ of the citing papers cited the modelling paper in more than one section (e.g. introduction and methods). This suggests that citations may not be a useful measure to assess engagement in either research or practice [57]. The citations may indicate specific papers that become part of the 


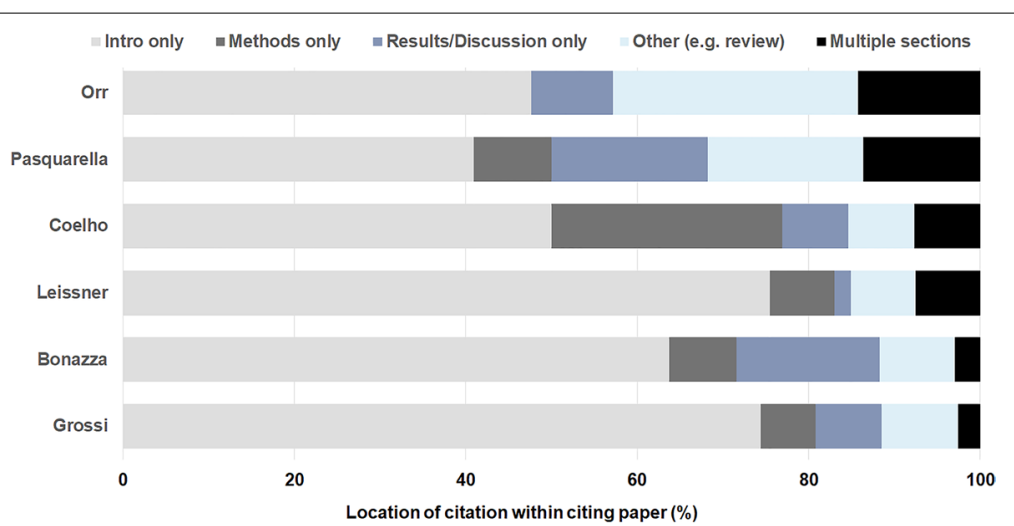

Fig. 3 The location of citations within a citing paper for the six most cited papers. Papers are identified by the first author

field's canon, with few critically engaging with either the model or its results [14].

Each article also included a number of self citations by the first author. These can sometimes be seen as selfpromoting. However, all self-citations occurred within 5 years of publication, except for Bonazza et al. [46] where 7 of the 11 self-citations by the first author occurred after this date. The occurrence of self-citation shortly after the original publication suggests that the research continues to be used by an author or group, to build on and develop their own ideas and that they remain active in heritage science.

Some papers meaningfully engage with the published models, e.g. Jeong et al. [58] applied the Orr et al. [47] model for wind-driven rain to assess the impact of future changes on buildings in Canada. This shows how models built on theory can be applied to a range of contexts as a tool to investigate change in heritage sciences. This is normal in many fields (e.g. climate impact research; [59]), so this is worrying that it appears so infrequently in heritage science. However, models associated with heritage science might be developed in practical applications and not be captured within traditional academic literature.

\section{Broader literature}

As we have seen above much of the published heritage research that utilises models arises in academia, with just a small proportion deriving from research by large heritage organisations (Fig. 4). It may be that practical applications of models is not visible in conventional scholarly publications. Sometimes it is difficult to publish practical applications in key research journals, because they might be thought to lack intellectual novelty. We have already noted that the use of IMPACT appeared in less well-known journals. Thus, practical applications might appear in other publications such as in conference papers or internal research reports. For example, The Fourth International Conference on Salt Weathering of Buildings and Stone Sculptures in Potsdam, makes much of ECOSRUNSALT and some of it quite practical, as in the investigation and conservation of salt damaged epitaphs in the church of Werben [60].

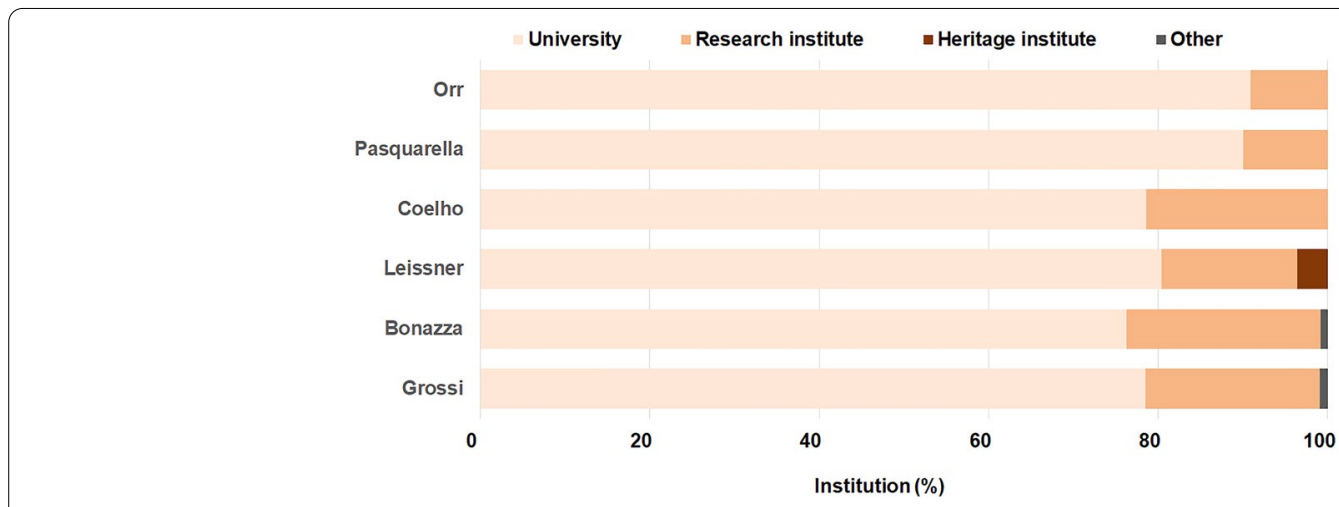

Fig. 4 First author affiliation on citing papers for each of the six highly cited modelling paper. Cited papers are identified by their first author 
The problem with these publications is that they may not be widely available and rarely form part of the major abstract and citation databases (e.g. WoS, Scopus). However, accessibility can be possible through GoogleScholar (https://scholar.google.com), AATA Online (https://aata. getty.edu/primo-explore/search?vid=AATA) and Bielefeld Academic Search Engine Library (https://www.basesearch.net/). These databases provide large amounts of material, but it can be difficult to sort and assess. Alternatively, non-academic publications (i.e. not captured in scholarly databases) can be explored using altmetrics (e.g. PlumX) that include the number of downloads, discussions, media accounts and blogs, in addition to traditional citation counts from scholarly works [16, 57]. As examples in PlumX, the practical paper on the Palatina Library in Parma scores more highly in the Social Media metric (includes shares, comments, tweets etc.) than the specialist paper from Orr et al. [47] on wind-driven rain. However, this may not mean the specialists papers fail to be of interest to wider publics, as Orr et al. was featured as a news item in The Times headlined as "More intense driving rain set to erode Scotland's historical heritage" [61].

Modellers need feedback to refine their models, but as shown this can be difficult to achieve using traditional academic pathways. Therefore, modellers in heritage science, would benefit from access to a wider range of literature and metrics. It would be helpful if there were better catalogues of the grey literature, or greater integration of grey literature in major databases such as GoogleScholar or Scopus (which has recently added preprints to its collection).

\section{Mechanisms for supporting transfer of knowledge}

The continuous refinement of models in heritage science needs a mechanism that enables feedback between the developers and users of models, such that: (i) developers understand the challenges and benefits that users have with using the model, and (ii) users can share ideas and experience. However, as alluded to above, within heritage science, model developers are not easily able to assess the engagement of practical users with their model, caused in part by differences in publishing and institutional practices. This means that there are limited opportunities for feedback between developers and users, reducing the potential for the ongoing process of model development.

Meaningful dialogues could be supported by heritage organisations running workshops on modelling use at conferences. Such events could provide opportunities for model developers to unpack elements of modelling that can seem like a black-box and also for model users to discuss challenges or hurdles that developers need to consider in constructing useful models.

There is also a pressing need for many heritage science models to become more user friendly. Models with a good grounding in theory, operating over temporal and spatial scales relevant to heritage, can have a limited uptake without an intuitive user interface. Models with GUIs, such as ECOS-RUNSALT, have been used by both researchers and practitioners, but graphical user interfaces are time consuming to set up and maintain. Heritage science and heritage institutions need to recognise the specialised and professional skills required to build such interfaces. One way this could be achieved would be by making grants available for employing software engineers on modelling projects, or by working with university incubator projects to support new modelling-based ventures.

\section{Conclusions}

Models have the potential to provide heritage scientists and practitioners with a powerful tool for advancing our understanding of a wide range of physical, chemical and biological processes on heritage sites and objects. Model characteristics, with regard to underpinning theory, process, spatial and temporal scale and usability, influence the applicability of a model in a heritage context. In particular, the development of a user interface seemed to aid model uptake in practical settings in addition to research. Without this, heritage science models tend to be reduced to simplified use of output, with only key results considered relevant, and the model remaining unused.

We did not find heritage science models being systematically developed and refined over time as they are in other disciplines, such as climatology or quantum mechanics. The heritage literature generally feeds models one-way, from research to practice. Internal research dealing with practice remains difficult to access, which reduces the potential for feedback loops to develop between model developers, users and practitioners. This presents an exciting opportunity for those who are, and who will, engage with models in heritage science. By grappling with challenging concepts of scale, generalisability and value, process-based models offer the potential to be a crucial tool for assessing how the future might unfold: both in the heritage fields, and beyond. These challenges could be addressed through actions including: conference and workshop sessions that bring modellers and practitioners together; grants for GUI development and cataloging the grey literature via a stronger presence in major databases. 


\section{Supplementary Information}

The online version contains supplementary material available at https://doi. org/10.1186/s40494-022-00650-4.

Additional file 1:Table S1. Metadata of the process-based modelling papers returned after Step 4 (Fig. 1)

\section{Acknowledgements}

The concept for this paper grew out of a talk presented by the authors at the Sustainable Heritage Bidecennial Conference: Strategic Research Questions, hosted online by University College London in March 2021. We thank the organisers of this event for this collaborative opportunity. We thank the two anonymous reviewers for their helpful comments that improved this manuscript.

\section{Authors' contributions}

Both authors contributed to the entire paper, although JR curated the data and PB was involved in identifying alt-metrics. Both authors read and approved the final manuscript.

\section{Funding}

No funding was received.

\section{Availability of data and materials}

As list of papers used in this research can be found in the supplementary material.

\section{Declarations}

\section{Competing interests}

The authors have no competing interests.

\section{Author details}

${ }^{1}$ St John's College, Oxford University, Oxford OX1 3JP, UK. ${ }^{2}$ School of Geography and the Environment, Oxford University, Oxford OX1 3QY, UK. ${ }^{3}$ Department of Marine Environment and Engineering, National Sun Yat-sen University, Kaohsiung, Taiwan.

Received: 16 November 2021 Accepted: 18 January 2022

Published online: 02 February 2022

\section{References}

1. Chorley RJ, Haggett P. Chorley and Haggett, editors (1967) Models in Geography. London: Methuen. 1967.

2. Demeritt D, Wainwright J. Models, modeling and geography. In: Castree $\mathrm{N}$ et al E, editor. Quest Geogr. Oxford: Blackwell Publishers Ltd; 2005. pp. 206-25

3. Bonetti E, Cavaterra C, Natalini RSM, editors. Mathematical modeling in cultural heritage: MACH2019. Cham: Springer Nature; 2021.

4. Grau-Bové J, Strlič M, Mazzei L. Applicability of a drift-flux model of aerosol deposition in a test tunnel and an indoor heritage environment. Build Environ. 2016;106:78-90. https://doi.org/10.1016/j.build env.2016.06.024.

5. Richards J, Bailey RM, Mayaud JR, Viles HA, Guo Q, Wang X. Deterioration risk of dryland earthen heritage sites facing future climatic uncertainty. Sci Rep. 2020;10:16419. https://doi.org/10.1038/s41598-020-73456-8.

6. Ligterink F, Di Pietro G. The limited impact of acetic acid in archives and libraries. Herit Sci. 2018;6:59. https://doi.org/10.1186/S40494-018-0225-Y.

7. Coco A, Donatelli M, Semplice M, Serra Capizzano S. Numerical simulations of marble sulfation. In: Bonetti E, Cavaterra C, Natalini R, Solci M, editors. Math model cult herit MACH2019. Cham: Springer; 2021.

8. Conti M, Danese V, Pata V. Aging of viscoelastic materials: a mathematical model. In: Bonetti E, Cavaterra C, Natalini R, Solci M, editors. Math model cult herit MACH2019. Cham: Springer; 2021.
9. Grøntoft T. A condition modelling tool for cultural heritage objects. Int J Conserv Sci. 2015;6:643-56. https://www.nilu.com/apub/28671/.

10. Jonkers K, Derrick GE. The bibliometric bandwagon: characteristics of bibliometric articles outside the field literature. J Am Soc Inf Sci Technol. 2012;63:829-36. https://doi.org/10.1002/ASI.22620.

11. Ellegaard $\mathrm{O}$, Wallin J. The bibliometric analysis of scholarly production: how great is the impact? Scientometrics. 2015;105:1809-31. https:// doi.org/10.1007/S11192-015-1645-Z.

12. GlänzelW, Schoepflin U. Little scientometrics, big scientometrics ... and beyond?Scientometrics. 1994;30:375-84.https://doi.org/10.1007/BF020 18107 .

13. Weingart P. Impact of bibliometrics upon the science system: inadvertent consequences? Scientometrics. 2005;62:117-31. https://doi.org/10. 1007/S11192-005-0007-7.

14. Larivière $V$, Gingras $Y$. The impact factor's Matthew Effect: a natural experiment in bibliometrics. J Am Soc Inf Sci Technol. 2010;61:424-7. https://doi.org/10.1002/ASI.21232.

15. Van Noorden R, Metrics. A profusion of measures. Nature. 2010;465:864-6. https://doi.org/10.1038/465864A.

16. Hicks D, Wouters P, Waltman L, de Rijcke S, Rafols I. Bibliometrics: The Leiden Manifesto for research metrics. Nature. 2015;520:429-31. https://doi.org/10.1038/520429a.

17. Fatorić S, Seekamp E. Are cultural heritage and resources threatened by climate change? A systematic literature review. Clim Change. 2017;142:227-54. https://doi.org/10.1007/s10584-017-1929-.

18. Su X, Li X, Kang Y. A bibliometric analysis of research on intangible cultural heritage using citespace. Sage Open. 2019;9:1-18. https://doi. org/10.1177/2158244019840119.

19. Orr SA, Richards J, Fatorić S. Climate change and cultural heritage: a systematic literature review (2016-2020). Hist Environ Policy Pract. 2021;12:434-77. https://doi.org/10.1080/17567505.2021.1957264.

20. Adie E, Roe W. Altmetric: enriching scholarly content with article-level discussion and metrics. Learn Publ. 2013;26:11-7. https://doi.org/10. 1087/20130103.

21. Hussein AS, El-Shishiny H. Wind Flow Modeling and Simulation over the Giza Plateau Cultural Heritage Site in Egypt. J Comput Cult Herit. 2009;2:1-22. https://doi.org/10.1145/1613672.1613674.

22. Pasquarella C, Balocco C, Pasquariello G, Petrone G, Saccani E, Manotti $P$, et al. A multidisciplinary approach to the study of cultural heritage environments: experience at the Palatina Library in Parma. Sci Total Environ. 2015;536:557-67.

23. Pineda P, Iranzo A. Analysis of sand-loaded air flow erosion in heritage sites by computational fluid dynamics: method and damage prediction. J Cult Herit. 2017;25:75-86. https://doi.org/10.1016/J.SCITOTENV. 2015.07.105

24. Balocco C, Petrone G, Maggi O, Pasquariello G, Albertini R, Pasquarella C. Indoor microclimatic study for Cultural Heritage protection and preventive conservation in the Palatina Library. J Cult Herit. 2016;22:95667. https://doi.org/10.1016/J.CULHER.2016.05.009.

25. Godts S, Hayen R, Clercq H, De. Investigating salt decay of stone materials related to the environment, a case study in the St. James church in Liège, Belgium. Stud Conserv. 2017;62:329-42. https://doi.org/10.1080/ 00393630.2016 .1236997$.

26. Benchekroun M, Chergui S, Ruggiero F, Turi S, Di. Improving the indoor climate of the traditional Ottoman houses in the Medina of Algiers. IOP Conf Ser Mater Sci Eng. 2019;609:042073. https://doi.org/10.1088/ 1757-899X/609/4/042073.

27. Brimblecombe P, Lankester P. Long-term changes in climate and insect damage in historic houses. Stud Conserv. 2013;58:13-22. https://doi. org/10.1179/2047058412Y.0000000051.

28. Du Y, Chen W, Cui K, Zhang J, Chen Z, Zhang Q. Damage assessment of earthen sites of the Ming Great Wall in Qinghai Province. J Comput Cult Herit. 2020;13:1-18. https://doi.org/10.1145/3376120.

29. Cabello-Briones C, Prieto AJ, Ortiz P. Determination of the technical suitability of shelters for archaeological sites using fuzzy logic. J Cult Herit. 2021;48:211-26. https://doi.org/10.1016/J.CULHER.2020.11.006.

30. Prieto AJ, Verichev K, Silva A, de Brito J. On the impacts of climate change on the functional deterioration of heritage buildings in South Chile. Build Environ. 2020;183:107138. https://doi.org/10.1016/J.BUILD ENV.2020.107138. 
31. Cabrera V, Yustres Á, López-Vizcaíno R, Merlo Ó, Ruiz M, Torrero E, et al. Determination of the hygric properties of the heritage stone of the Cathedral of Cuenca through the water absorption by capillarity test. J Cult Herit. 2021;48:186-95. https://doi.org/10.1016/J.CULHER.2020.11. 009.

32. Marcon B, Goli G, Fioravanti M. Modelling wooden cultural heritage. The need to consider each artefact as unique as illustrated by the Cannone violin. Herit Sci. 2020;8:24. https://doi.org/10.1186/S40494-020-00368-1.

33. Verticchio E, Frasca F, Cornaro C, Siani AM. Investigation on the use of hygrothermal modelling for paper collections. IOP Conf Ser Mater Sci Eng. 2020;949:012015. https://doi.org/10.1088/1757-899X/949/1/012015.

34. Monforti F, Bellasio R, Bianconi R, Clai G, Zanini G. An evaluation of particle deposition fluxes to cultural heritage sites in Florence, Italy. Sci Total Environ. 2004;334-335:61-72. https://doi.org/10.1016/J.SCITOTENV.2004. 04.030 .

35. Menéndez B. Estimation of salt mixture damage on built cultural heritage from environmental conditions using ECOS-RUNSALT model. J Cult Herit. 2017;24:22-30. https://doi.org/10.1016/J.CULHER.2016.11.006.

36. Godts S, Orr SA, Desarnaud J, Steiger M, Wilhelm K, De Clercq H, et al. $\mathrm{NaCl}$-related weathering of stone: the importance of kinetics and salt mixtures in environmental risk assessment. Herit Sci. 2021;9:44. https:// doi.org/10.1186/S40494-021-00514-3.

37. Zhao ZC, Song YC, Huang X, Soh AK, Zhang DS. Study of solidification of menthol for the applications in temporary consolidation of cultural heritage. J Cult Herit. 2020;44:83-9. https://doi.org/10.1016/J.CULHER.2020.01. 017.

38. Pierdicca R, Paolanti M, Bacchiani R, de Leo R, Bisceglia B, Frontoni E. Accurate modeling of the microwave treatment of works of art. Sustain. 2019:11:1606. https://doi.org/10.3390/SU11061606.

39. Ghosh S, Pillai RH, Roy A, Anand Murali R, Vardhan V. A simulation study of dust transport on an ancient amphitheatre: the Delphi example. J Cult Herit. 2017;24:108-16. https://doi.org/10.1016/J.CULHER.2016.10.009.

40. Chatoutsidou SE, Mašková L, Ondráčková L, Ondráček J, Lazaridis M, Smolík J. Modeling of the aerosol infiltration characteristics in a cultural heritage building: the Baroque Library Hall in Prague. Build Environ. 2015;89:253-63. https://doi.org/10.1016/J.BUILDENV.2015.02.029.

41. Kompatscher K, Kramer RP, Ankersmit B, Schellen HL. Intermittent conditioning of library archives: microclimate analysis and energy impact. Build Environ. 2019;147:50-66. https://doi.org/10.1016/J.BUILDENV.2018.10.013.

42. Rihosek J, Bruthans J, Masin D, Filippi M, Carling GT, Schweigstillova J. Gravity-induced stress as a factor reducing decay of sandstone monuments in Petra, Jordan. J Cult Herit. 2016;19:415-25. https://doi.org/10. 1016/J.CULHER.2015.10.004

43. Grossi CM, Brimblecombe P, Harris I. Predicting long term freeze-thaw risks on Europe built heritage and archaeological sites in a changing climate. Sci Total Environ. 2007;377:273-81. https://doi.org/10.1016/j.scito tenv.2007.02.014.

44. Lankester P, Brimblecombe P. Future thermohygrometric climate within historic houses. J Cult Herit. 2012;13:1-6. https://doi.org/10.1016/J.CULHER.2011.06.001.

45. Leissner J, Kilian R, Kotova L, Jacob D, Mikolajewicz U, Broström T, et al. Climate for culture: assessing the impact of climate change on the future indoor climate in historic buildings using simulations. Herit Sci. 2015;3:38. https://doi.org/10.1186/S40494-015-0067-9.

46. Bonazza A, Messina P, Sabbioni C, Grossi CM, Brimblecombe P. Mapping the impact of climate change on surface recession of carbonate buildings in Europe. Sci Total Environ. 2009;407:2039-50. https://doi.org/10. 1016/J.SCITOTENV.2008.10.067.

47. Orr SA, Young M, Stelfox D, Curran J, Viles H. Wind-driven rain and future risk to built heritage in the United Kingdom: novel metrics for characterising rain spells. Sci Total Environ. 2018;640-641:1098-111. https://doi.org/ 10.1016/J.SCITOTENV.2018.05.354

48. Grau-Bové J, Mazzei L, Malkii-Ephstein L, Thickett D, Strlič M. Simulation of particulate matter ingress, dispersion and deposition in a historical building. J Cult Herit. 2016;18:199-208. https://doi.org/10.1016/J.CULHER.2015. 08.006 .

49. Blades N, Kruppa D, Cassar M. Development of a Web-based software tool for predicting the occurrence and effect of air pollutants inside museum buildings. In: ICOM, editor. ICOM Comm Conserv 13th Trienn Meet Rio Janeiro 20-27 Sept 2002. London: James \& James; 2002.
50. Ryhl-Svendsen M. Indoor air pollution in museums: prediction models and control strategies. Stud Conserv. 2013;51:27-41. https://doi.org/10. 1179/SIC.2006.51.SUPPLEMENT-1.27.

51. Shafiepour M, Ashrafi K, Tavakoli A. Indoor air quality modelling for Tehran museums by IMPACT. J Environ Stud. 2010;36:22-4.

52. Bionda D. RUNSALT - A graphical user interface to the ECOS thermodynamic model for the prediction of the behaviour of salt mixtures under changing climate conditions. 2005. http://science.sdf-eu.org/runsalt/.

53. Price $C A$, editor. An expert chemical model for determining the environmental conditions needed to prevent salt damage in porous materials. Archetype Publications, London. Eur Comm Res Rep No 11, (Protection Conserv Eur Cult Heritage). London: Archetype Publications; 2000.

54. Brimblecombe P, Clegg SL, Reeves NJ. Thermodynamics, expert systems and salt damage to porous stone. In: Antonia I, Zezza F, Kollias E, Papachristodoulou I, editors. 4th Int Symp Conserv Monum Mediterr new concepts, Technol Mater Conserv Hist cities, sites complexes. Athens: Technical Chamber of Greece; 1997.

55. Clegg SL, Brimblecombe P, Wexler AS. Thermodynamic model of the system H+-NH4+-Na+-SO42--NO3--Cl--H2O at 298.15 K. J Phys Chem A. 1998;102:2155-71. https://doi.org/10.1021/JP973043J.

56. Grøntoft T, Stoveland LP, Frøysaker T. Predicting future condition and conservation costs from modelling improvements to the indoor environment: the monumental munch-paintings in the University of Oslo's Aula Assembly Hall. J Conserv Museum Stud. 2019;17:1-15. https://doi.org/10. 5334/jcms. 185

57. Ravenscroft J, Liakata M, Clare A, Duma D. Measuring scientific impact beyond academia: an assessment of existing impact metrics and proposed improvements. PLoS ONE. 2017;12:e0173152. https://doi.org/10. 1371/JOURNAL.PONE.0173152.

58. Jeong D, II, Cannon AJ. Projected changes to moisture loads for design and management of building exteriors over Canada. Build Environ. 2020;170:106609. https://doi.org/10.1016/J.BUILDENV.2019.106609.

59. The National Audubon Society. SURVIVAL BY DEGREES: 389 Bird Species on the Brink. 2019. https://www.audubon.org/climate/survivalbydegrees.

60. Laue S, Poerschke D, Hübner B. Investigation and conservation of salt damaged epitaphs in the church of Werben (Saxony-Anhalt, Germany). In: Laue S, editor. SWBSS 2017 fourth Int Conf salt Weather Build stone Sculpt. Potsdam: Potsdam Verlad der Fachhochschule Potsdam; 2017.

61. Macaskill M. More intense driving rain set to erode Scotland's historical heritage. The Times. 2018 Jan 14; https://www.thetimes.co.uk/article/ more-intense-driving-rain-set-to-erode-scotlands-historical-heritagegrm8xgxnl.

\section{Publisher's Note}

Springer Nature remains neutral with regard to jurisdictional claims in published maps and institutional affiliations.

\section{Submit your manuscript to a SpringerOpen ${ }^{\circ}$ journal and benefit from:}

- Convenient online submission

- Rigorous peer review

- Open access: articles freely available online

- High visibility within the field

- Retaining the copyright to your article

Submit your next manuscript at $\boldsymbol{\nabla}$ springeropen.com 